\title{
Eaton-Lambert syndrome: a clinical and electrophysiological study of a patient treated with 4-aminopyridine
}

\author{
DONALD B SANDERS, YONG I KIM, JAMES F HOWARD, JR, \\ AND C ALLEN GOETSCH
}

From the Department of Neurology and the University of Virginia Jerry Lewis Neuromuscular Center, University of Virginia School of Medicine, Charlottesville, Virginia

SUMMARY In a patient with the Eaton-Lambert syndrome, 4-aminopyridine produced temporary improvement of clinical and electromyographic abnormalities. Application of the drug in vitro to intercostal muscle from the patient produced an increase in the evoked release of neurotransmitter from intramuscular nerves.

The Eaton-Lambert syndrome is a defect of neuromuscular transmission, frequently associated with carcinoma of the lung, characterised by a reduction in the amount of acetylcholine (ACh) released from motor nerve terminals. ${ }^{12}$ Cholinesterase inhibitors, which are effective in the treatment of myasthenia gravis, do not produce significant improvement in most patients with the Eaton-Lambert syndrome. ${ }^{2}{ }^{3}$ Guanidine, a compound that increases the release of $\mathrm{ACh}$ from motor nerve terminals, has helped patients with this condition, ${ }^{4-6}$ but its use is limited by severe side effects. ${ }^{7-9}$ Recently, 4-aminopyridine (4-AP), a quaternary ammonium compound, has been shown to increase neurally evoked acetylcholine release ${ }^{10-13}$ and two reports of its use in the treatment of the Eaton-Lambert syndrome have been published. ${ }^{14}{ }^{15}$ This paper describes another patient in whom 4-AP was used to treat the Eaton-Lambert syndrome, and the in vitro effects of the drug on neuromuscular transmission in an intercostal nerve-muscle biopsy from the patient are described.

\section{Case report}

Clinical history A 61-year-old retired farmer with a previous history of mild hypertension and chronic cigarette smoking was well until mid-October 1978,

Address for reprint requests: Dr Sanders, Division of Neurology, Box 3403, Duke University Medical Center, Durham, North Carolina 27710, USA

Accepted 11 April 1980 when he noted "dizziness and weakness." Progressively over four days he developed weakness of the limbs, which was worse in his legs. He had particular difficulty climbing stairs and arising from a low chair or couch. This was followed by difficulty raising his arms over his head and combing his hair. In November a right hilar mass was noted on a chest radiograph. Bronchoscopy was performed without difficulty under general anaesthesia; bronchial washings suggested a small cell carcinoma. The patient was scheduled for a second procedure three weeks later, but in the interim he noted further weakness of his arms and legs and required the aid of a cane when walking. Following the second bronchoscopy, during which succinylcholine was given, the patient had a prolonged period of apnoea and required mechanical ventilation for several hours. Biopsy of an irregular, nodular lesion of the right mainstem bronchus revealed a small cell carcinoma of the lung. Because of progressive weakness and dyspnoea, he was transferred to the University of Virgina Hospital.

On examination he had mild, symmetrical facial and masseter weakness and dysarthric speech. There was moderate weakness of neck flexion and mild weakness of neck extension, severe weakness of shoulder and hip girdle muscles, and mild weakness of the distal arm muscles. Repetitive activity did not improve the strength in any muscle group tested. Other than barely perceptible biceps reflexes, no other muscle stretch reflexes were obtained at rest, nor after sustained voluntary effort. Muscle tone was normal and there was no atrophy.

Serum creatine phosphokinase, electrolytes, calcium and magnesium levels were normal. Electrical stimulation of the ulnar nerve at the wrist produced an evoked potential amplitude of $3.2 \mathrm{mV}$ in the abductor digiti minimi (ADM) at an intramuscular temperature 


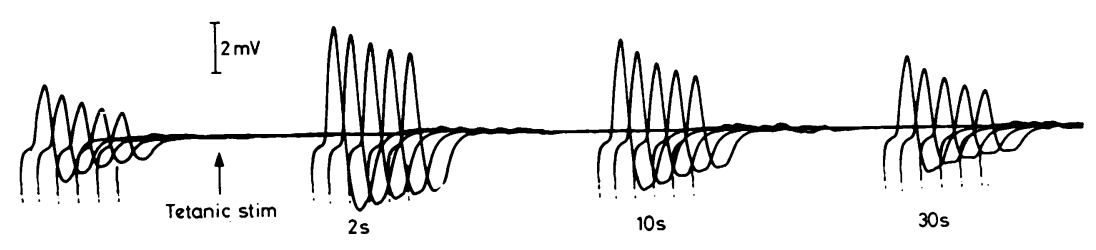

Fig 1 Surface recordings of compound muscle action potentials from the ADM evoked by $5 \mathrm{~Hz}$ supra-maximal stimulation of the ulnar nerve before, and at indicated intervals after maximal voluntary contraction of the muscle for $30 s$. of $32^{\circ} \mathrm{C}$. Repetitive stimulation at frequencies of 1 , 2 and 5 per second produced decrements of $31 \%$, $41 \%$ and $42 \%$, respectively, in the amplitude of the fifth evoked potential compared to the first. After warming the hand to produce an intramuscular temperature of $36^{\circ} \mathrm{C}$, the ADM evoked potential amplitude was $2.8 \mathrm{mV}$, and 5 per second nerve stimulation produced a decrement of $36 \%$ in the fifth response (fig 1). Following maximum voluntary contraction of the ADM for 30 seconds, the evoked potential amplitude in that muscle increased to $5.9 \mathrm{mV}$ and the decrement was reduced to $20 \%$. Stimulation of the ulnar nerve at a frequency of 50 per second produced an increment in the amplitude of the ADM evoked potential to $230 \%$ of the initial value (fig 2). After intravenous injection of edrophonium $(6 \mathrm{mg})$, the decrement increased from $31 \%$ to $38 \%$ at 60 seconds and returned to baseline values at 120 seconds. No change in strength was noted after edrophonium injection. Concentric needle EMG of the anterior deltoid muscle revealed no spontaneous electrical activity in the muscle at rest. Voluntary motor unit

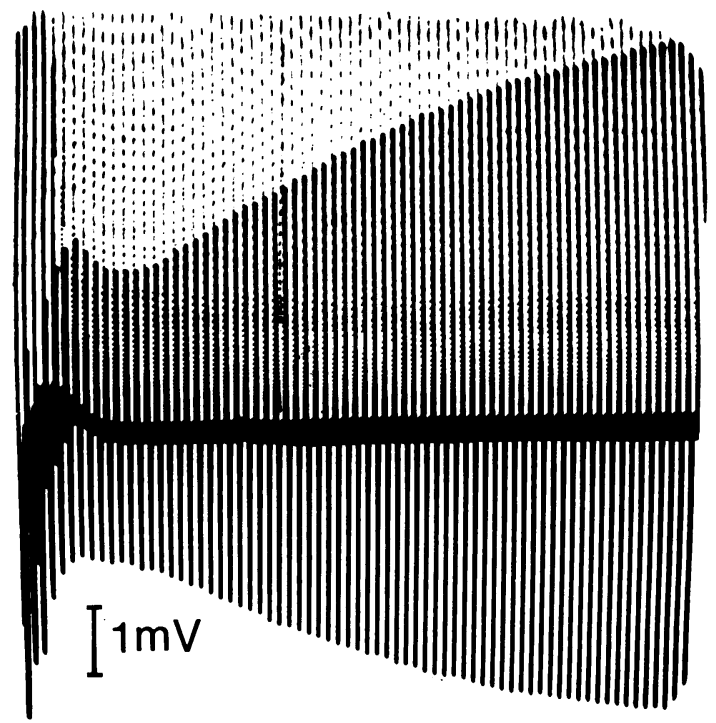

Fig 2 Surface recordings of compound muscle action potentials evoked from the ADM by $50 \mathrm{~Hz}$ stimulation of the ulnar nerve. Thin, dashed vertical lines are stimulus artefacts. potentials were very unstable, demonstrating fluctuating amplitudes and waveforms. Motor nerve conduction velocity measurements were normal.

The patient was treated with methylprednisolone, CCNU, cyclophosphamide and vincristine and subsequently received radiotherapy to the pulmonary lesion. His generalised weakness became progressively worse and he required mechanical respiratory assistance. Intravenous edrophonium (10 $\mathrm{mg})$ and oral pyridostigmine and neostigmine did not produce any improvement. The patient agreed to the use of 4-AP as an experimental treatment, and received an initial oral dose of $7.5 \mathrm{mg}$, followed by $15 \mathrm{mg}$ every three hours. Notable improvement in strength of the extremities was seen, his vital capacity increased $180 \%$ to 1.5 litres and the amplitude of the ADM evoked potential increased $150 \%$. Increasing his dose of 4-AP to $20 \mathrm{mg}$ every four hours did not produce further clinical improvement, but did increase the ADM evoked potential amplitude to $4.8 \mathrm{mV}$ from immediate pre-treatment values of $1 \cdot 1 \mathrm{mV}$. Discontinuing the drug for six hours resulted in increased weakness, a reduction in his vital capacity to less than one litre and a fall in the ADM evoked potential amplitude to pre-treatment levels. Because of a suspected upper gastrointestinal haemorrhage, oral 4-AP was discontinued after two days, following which his vital capacity declined to less than one litre. Seventy-two hours after discontinuing the drug he had a respiratory arrest and increased weakness in his neck, arms and legs.

Four days after discontinuing the drug, parenteral administration of 4-AP was begun in doses of $10 \mathrm{mg}$ intravenously every four hours (fig 3). This again resulted in prompt improvement of his grip, limb muscle strength, vital capacity and ADM evoked amplitude. After five doses he noted increased sweating and abdominal cramping, which were maximal 60 to 90 minutes after receiving an injection of 4-AP. Withholding the drug relieved these symptoms but caused greater weakness in all affected muscle groups. In an attempt to wean the patient from the ventilator. 4-AP was restarted in doses of $20 \mathrm{mg}$ to $25 \mathrm{mg} \mathrm{IV}$ every four to six hours despite the apparent side effects. While improvement was noted in all affected muscles, his strength was not sufficient for independent respiration, and the drug was discontinued after seven days of parenteral therapy. He developed spiking fevers, collapse of the right lower lobe of the lung, and died on his 28th hospital day. 


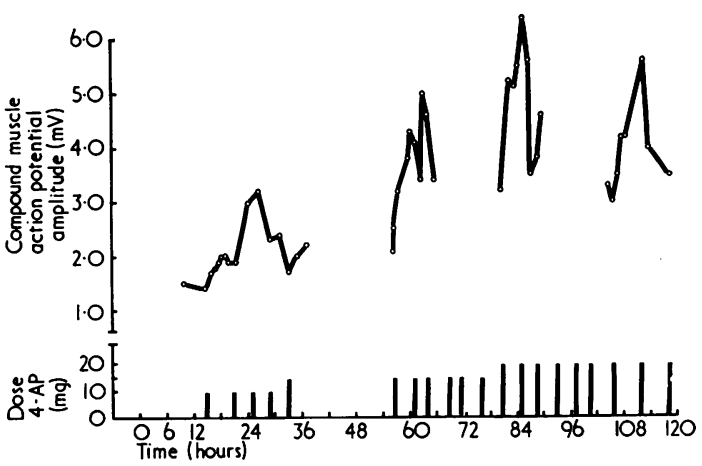

Fig 3 The effect of 4-AP on the amplitude of the ADM compound muscle action potential evoked by single supramaximal stimuli to the ulnar nerve. Vertical bars represent intravenous doses of 4-AP.

A limited post mortem examination revealed multiple foci of small atypical cells in the septal lymphatics and alveolar spaces in the upper and middle lobes of the right lung suggestive of a tumor mass following therapeutic radiation. Multiple foci of haemorrhagic necrosis of the liver parenchyma were noted. No abnormalities were noted in the kidney or gastric mucosa.

Histological examination of intercostal muscle demonstrated scattered angular atrophic fibres with increased DPNH staining. These fibres were of both histochemical types by myofibrillar ATPase staining. No inflammatory reaction was seen.

Electrophysiological studies Intercostal muscle from the right fifth intercostal space was removed $1 \frac{1}{2}$ hours after death and placed in oxygenated physiological solution at $0^{\circ} \mathrm{C}$. After removal of excessive fat and connective tissue, this biopsy was dissected under microscopic observation to separate small muscle bundles with an intact nerve supply. The muscle bundles were slightly stretched and pinned onto the
Sylgard resin (Dow Corning Co) base of a bathing chamber.

The ionic composition of the control bathing solution was as follows (in $\mathrm{mM}$ ): $\mathrm{NaCl}=135, \mathrm{NaHCO}_{3}=$ 15, $\mathrm{Na}_{2} \mathrm{HPO}_{4}=1, \quad \mathrm{KCl}=5, \quad \mathrm{CaCl}_{2}=2, \quad \mathrm{MgCl}_{2}=1$, and glucose $=11$, with resulting $\mathrm{pH}$ of $7 \cdot 2$ to $7 \cdot 4$. In all solutions containing altered $\left[\mathrm{Ca}^{++}\right]_{0}$ or $\left[\mathrm{K}^{+}\right]_{0}$, $\left[\mathrm{Na}^{+}\right]_{\circ}$ was altered to produce an osmolarity equal to that of the control solution. All solutions were bubbled with $95 \% \mathrm{O}_{2}$ and $5 \% \mathrm{CO}_{2}$ prior to circulation through the bathing chamber. The volume of the bathing chamber was less than $1 \mathrm{ml}$ and the bathing solution was continuously exchanged at a rate of 2.5 to $3 \mathrm{ml}$ per minute by use of a push-pull perfusion pump (Holter 911).

Intracellular recordings were made at bath temperatures of $25^{\circ} \mathrm{C}$ to $27^{\circ} \mathrm{C}$ using $3 \mathrm{M} \mathrm{KCl}$-filled micropipettes and conventional electrophysiological techniques for measurement of subsynaptic electrical events as previously described for our laboratory. ${ }^{12} 13$

\section{Results of intercostal muscle studies}

(1) Spontaneous endplate activity The resting membrane potentials (RMPs) recorded from the junctional region of muscle fibres were $-74 \cdot 1$ $\pm 0.9 \mathrm{mV}$, and there were no abnormalities in the waveforms of miniature endplate potentials (MEPPs). The mean amplitude and frequency of MEPPs measured from 15 fibres were $0.72 \mathrm{mV}$ and 6.24 MEPPs/min respectively, these values being normal (table 1A). ${ }^{16-18}$ Since MEPP amplitude represents the depolarisation produced by a single quantum of transmitter, these results indicate that the postjunctional membrane sensitivity to $\mathrm{ACh}$ was not affected by the disease process.

Studies of spontaneous transmitter release at single endplates were performed by varying the extracellular potassium and calcium concentra-

Table 1 Effects of 4-aminopyridine on MEPPs and indirectly elicited muscle APs in Eaton-Lambert syndrome muscle

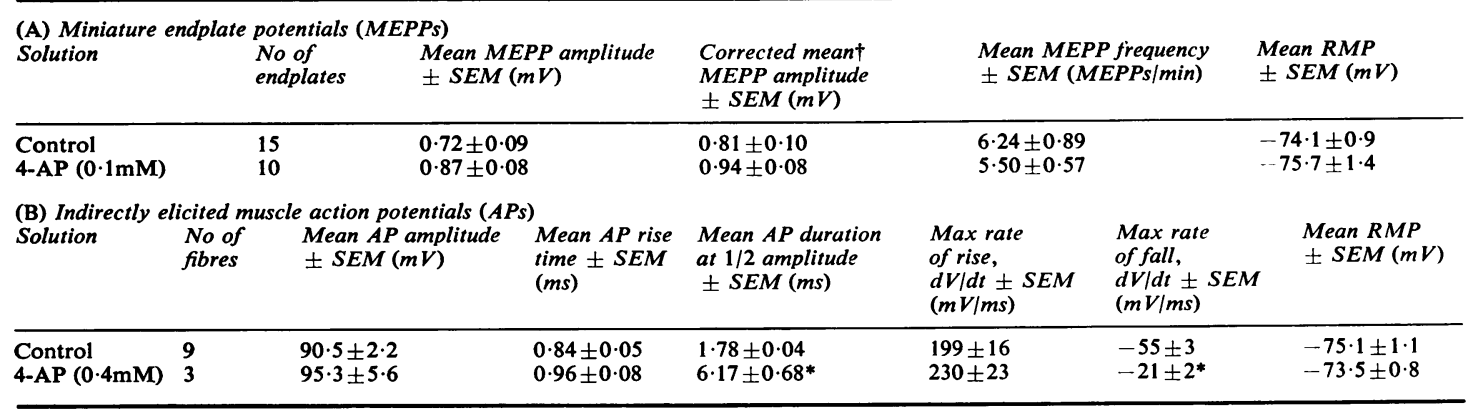

SEM: Standard error of mean.

* p $<0.001$ by Student's $t$-test when compared to the control.

tCorrected to a standard RMP of $-80 \mathrm{mV}$ and an ACh reversal potential of $-15 \mathrm{mV} .1730$ 


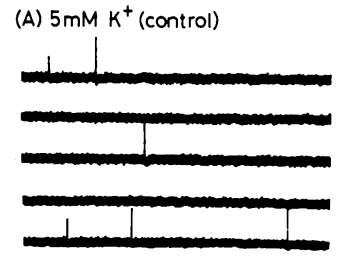

(B) $15 \mathrm{mM} \mathrm{K}^{+}$

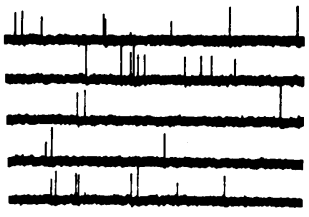

tions. An increase of $\left[\mathrm{K}^{+}\right]_{\mathrm{o}}$ from $5 \mathrm{mM}$ to $15 \mathrm{mM}$ or $20 \mathrm{mM}$ produced a rapid depolarisation of the endplate membrane, presumably due to reduction in the potassium equilibrium potential, $\mathrm{E}_{\mathrm{K}}$, and a concurrent rise in MEPP frequency (fig 4). With $15 \mathrm{mM}$ and $20 \mathrm{mM}\left[\mathrm{K}^{+}\right]_{\mathrm{o}}$, the endplate was depolarised by $14 \mathrm{mV}$ and $20 \mathrm{mV}$, respectively, values that are similar to those measured from human myasthenic endplates under the same conditions (Kim, YI and Sanders, DB: unpublished data). As would be expected from a depolarised endplate, MEPPS were reduced in amplitude after exposure to the high potassium concentration. The frequency of MEPPs increased 6.4 times in $15 \mathrm{mM}\left[\mathrm{K}^{+}\right]_{0}$ and 42.8 times in $20 \mathrm{mM}\left[\mathrm{K}^{+}\right]_{\mathrm{o}}$. The latter value is greater than that reported in the Eaton-Lambert syndrome (17 times) by Lambert and Elmqvist, ${ }^{19}$ but still less than the value (177 times) obtained by those authors from normal intercostal muscle.

In order to study the sensitivity of the motor nerve terminals to calcium ions, changes in the frequency of spontaneous transmitter release were examined at a single endplate exposed to six different concentrations of calcium $(0 \cdot 1,1$, $2,4,7$, and $10 \mathrm{mM}$ ) (table 2). An increase of $\left[\mathrm{Ca}^{++}\right]_{\text {。 }}$ from the control concentration of $2 \mathrm{mM}$ to $7 \mathrm{mM}$ or $10 \mathrm{mM}$ produced a $10 \%$ to $20 \%$ increase in MEPP frequency, this increase being considerably less than that seen at the normal or myasthenic human neuromuscular junction $(>70 \%)(\mathrm{Kim}, \mathrm{YI}$ and Sanders, DB, unpublished
(C) $20 \mathrm{mM} \mathrm{K}^{+}$

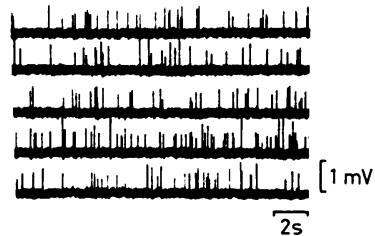

Fig 4 Effect of increasing extracellular potassium concentration on $M E P P s$ in Eaton-Lambert syndrome muscle. All recordings were made from the same endplate.

data). No pronounced or consistent changes in either the MEPP amplitude or RMP occurred

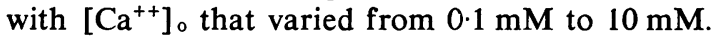

In summary, motor nerve terminals did not respond normally to changes in external calcium or potassium concentration, confirming that there is an abnormality in the presynaptic release of neuromuscular transmitter in the Eaton-Lambert syndrome.

(2) Neurally-evoked endplate activity By studying the transmitter-evoked response of the endplates to repetitive nerve stimulation $(0 \cdot 2 \mathrm{~Hz}$ to $2 \mathrm{~Hz}$ ), we were able to characterise three different types of responses in different fibres in the EatonLambert syndrome muscle.

A Fibres in which muscle action potentials (APs) were consistently produced and no failure of neuromuscular transmission occurred (fig 5A). In these fibres, the indirectly elicited muscle APs were of normal amplitude and waveform (fig 6). The RMP measured from the extraiunctional regions of these fibres was also normal (table 1B). These findings indicate that the membrane conductance mechanisms involved in the initiation and propagation of the AP were not affected by the disease.

B Fibres in which both muscle APs and subthreshold endplate potentials (EPPs) were produced and neuromuscular transmission was partially blocked (fig 5B). In these fibres, change in RMP was not a factor in the failure of neuromuscular transmission since it was possible to

Table 2 Effects of extracellular calcium concentration $\left(\left[\mathrm{Ca}^{++}\right]_{0}\right)$ on $\mathrm{MEPP}$ frequency and amplitude in Eaton-Lambert syndrome muscle*

\begin{tabular}{|c|c|c|c|c|}
\hline$\left[\mathrm{Ca}^{++}\right]_{0}(\mathrm{mM})$ & $\begin{array}{l}\text { Mean MEPP amplitude } \\
\pm S E M(m V)\end{array}$ & $\begin{array}{l}\text { Mean MEPP frequency } \\
\pm S E M(M E P P s / m i n) \\
(F)\end{array}$ & $\begin{array}{l}\text { Relative } \\
M E P P \text { frequency } \dagger \\
\left(F / F_{0}\right)\end{array}$ & $R M P(m V)$ \\
\hline $\begin{array}{l}0 \cdot 1 \\
1 \\
2 \text { (Control) } \\
4 \\
7 \\
10\end{array}$ & $\begin{array}{l}1 \cdot 10 \pm 0.14 \\
1.02 \pm 0.09 \\
1 \cdot 11 \pm 0.13 \\
0.98 \pm 0 \cdot 10 \\
0.97 \pm 0.11 \\
1.00 \pm 0.06\end{array}$ & $\begin{array}{l}2 \cdot 39 \\
3 \cdot 87 \\
4 \cdot 19\left(\mathrm{~F}_{0}\right) \\
5 \cdot 07 \\
4 \cdot 68 \\
4.97\end{array}$ & $\begin{array}{l}0.57 \\
0.92 \\
1.00 \\
1.21 \\
1.12 \\
1.19\end{array}$ & $\begin{array}{l}-72 \cdot 5 \\
-69 \cdot 3 \\
-77 \cdot 4 \\
-71 \cdot 0 \\
-70 \cdot 7 \\
-74 \cdot 0\end{array}$ \\
\hline
\end{tabular}

SEM: Standard error of mean.

*All data were obtained from a single endplate.

†Expressed as the ratio $\left(F / F_{0}\right)$ of the frequency in the test solution $(F)$ to the frequency in control solution $\left(F_{0}\right)$. 
(A)

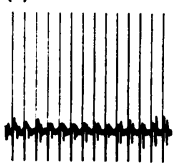

(B)

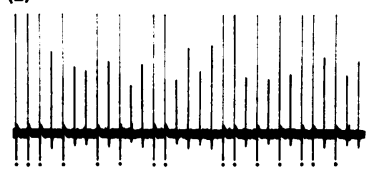

(C)

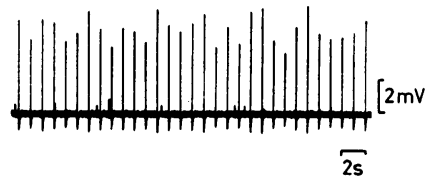

Fig 5 Three different types of responses seen in different endplates in Eaton-Lambert syndrome muscle. The neurallyevoked response of these endplates consisted of $(A) A P s$ only, $(B) A P s$ and EPPs, or $(C) E P P s$ only. In $(B)$ each AP is marked by a dot. The frequency of stimulation was $1 \mathrm{~Hz}$. Because of high amplification, $A P s$ in $(A)$ and $(B)$ are truncated. See text for details.

maintain a virtually constant RMP during prolonged repetitive stimulation, muscle contraction being too weak to displace the microelectrode.

C Fibres in which subthreshold EPPs were consistently produced and neuromuscular transmission was completely blocked (fig 5C). EPPs in these fibres fluctuated considerably in amplitude, providing further evidence that quantal size was not reduced. ${ }^{17} 20$

In order to demonstrate further the nature of the neuromuscular blockade present in the EatonLambert syndrome muscle, we calculated the quantum content $(\mathrm{m})$ of EPPs in fibres of types $B$ and C. Direct quantal analysis ${ }^{20} 21$ performed in eight endplates (table 3 ) revealed that $m$ was approximately seven, a value that is less than $10 \%$ of normal. ${ }^{22}$ This confirmed that the defect of neuromuscular transmission in this patient resulted from inadequate release of normal $\mathrm{ACh}$ quanta from the motor nerve terminal. Bathing the muscle biopsy in physiological solution for up to 16 hours produced no improvement in quantal release.

(3) In vitro facilitatory action of 4-aminopyridine on neuromuscular transmission 4-aminopyridine (4-AP) enhances neurally-evoked transmitter release and has been demonstrated to improve strength when given to rats poisoned with
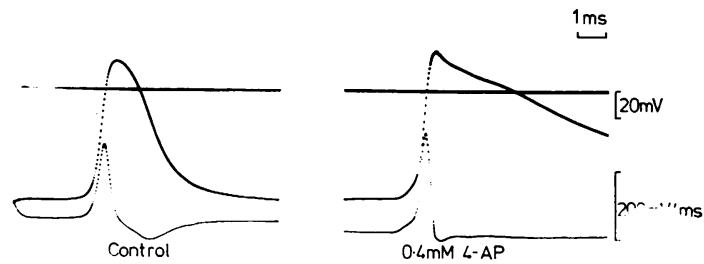

Fig 6 Effect of 4-aminopyridine $(0.4 \mathrm{mM})$ on the waveform of indirectly elicited action potentials in Eaton-Lambert syndrome muscle. The first derivative $(d V / d t)$ of the muscle action potential is shown in the lower trace. The solid horizontal line represents zero membrane potential. botulinum toxin ${ }^{11}$ and to patients with the EatonLambert syndrome and myasthenia gravis. ${ }^{14}{ }^{23}$ We wished to confirm in vitro the effects of the drug in alleviating the neuromuscular transmission defect in the Eaton-Lambert syndrome by studying the responses of spontaneous and evoked transmitter release to bath-applied 4-AP.

The facilitatory action of the drug on neuromuscular transmission was determined by
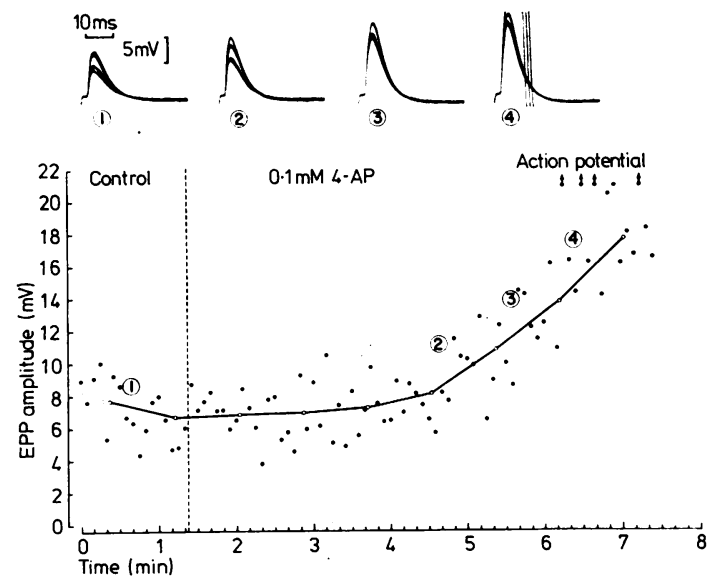

Fig 7 EPPs from a single endplate in Eaton-Lambert syndrome muscle before and after perfusion with $0.1 \mathrm{mM}$ 4-AP (dashed line). Each closed circle (O) represents the amplitude of a single EPP produced by nerve stimulation at 5 second intervals. Open circles $(O)$ indicate the mean amplitude of 10 consecutive EPPs. The numbers on the graph correspond to the evoked waveforms in the upper pictures (5 to 7 consecutive responses were superimposed in each picture). 4-AP increased the EPP amplitude to a suprathreshold level to produce APs (arrows). Due to high amplification and microelectrode displacement following muscle contraction, the AP waveforms in 4 are truncated. (Copyright (C) 1980 by Houghton Mifflin Professional Publishers, Inc. Reprinted from "Facilitatory effects of 4-aminopyridine on neuromuscular transmission in disease states" by YI Kim, MM Goldner and DB Sanders, as it appeared in Muscle and Nerve, Volume 3 No 2, by permission of the publisher.) 
Table 3 Quantum content of endplate potentials (EPPs) in Eaton-Lambert syndrome muscle

\begin{tabular}{|c|c|c|c|c|c|c|}
\hline $\begin{array}{l}\text { Endplate } \\
\text { no }\end{array}$ & $\begin{array}{l}\text { Mean EPP amplitude } \\
\pm S E M(m V)\end{array}$ & $\begin{array}{l}\text { Mean MEPP amplitude } \\
\pm S E M(m V)\end{array}$ & $\begin{array}{l}\text { Mean } \\
R M P \\
(m V)\end{array}$ & $\begin{array}{l}\text { Mean quantum } \\
\text { content, } m^{*}\end{array}$ & $\begin{array}{l}\text { Corrected } \\
\text { quantum } \\
\text { content, } \\
m_{c \dagger} \dagger\end{array}$ & $\begin{array}{l}\% \text { Failure of EPPs } \\
\text { observed (predicted) } \ddagger\end{array}$ \\
\hline $\begin{array}{l}1 \\
2 \\
3 \\
4 \\
5 \\
6 \\
7 \\
8\end{array}$ & $\begin{array}{l}4.35 \pm 0.23 \\
3.91 \pm 0.15 \\
1.95 \pm 0.09 \\
5.85 \pm 0.29 \\
5.09 \pm 0.16 \\
2.12 \pm 0.18 \\
2.89 \pm 0.12 \\
2.82 \pm 0.19\end{array}$ & $\begin{array}{l}0.45 \pm 0.05 \\
0.46 \pm 0.03 \\
0.39 \pm 0.03 \\
0.78 \pm 0.03 \\
0.57 \pm 0.02 \\
0.69 \pm 0.09 \\
0.38 \pm 0.02 \\
0.45 \pm 0.04\end{array}$ & $\begin{array}{l}-68 \cdot 2 \\
-81 \cdot 4 \\
-70 \cdot 9 \\
-66 \cdot 4 \\
-70 \cdot 7 \\
-66 \cdot 1 \\
-72 \cdot 1 \\
-65.2\end{array}$ & $\begin{array}{l}9 \cdot 67 \\
8 \cdot 50 \\
5 \cdot 00 \\
7 \cdot 50 \\
8 \cdot 93 \\
3 \cdot 07 \\
7 \cdot 61 \\
6 \cdot 27\end{array}$ & $\begin{array}{l}9 \cdot 81 \\
9 \cdot 45 \\
5 \cdot 50 \\
9 \cdot 77 \\
9 \cdot 78 \\
3 \cdot 47 \\
7 \cdot 89 \\
6 \cdot 15\end{array}$ & $\begin{array}{l}0(0) \\
0(0) \\
0(0 \cdot 7) \\
0(0) \\
0(0) \\
8 \cdot 9(4 \cdot 6) \\
0(0) \\
0(0 \cdot 2)\end{array}$ \\
\hline
\end{tabular}

SEM : Standard error of mean.

* $m=$ Mean EPP amplitude/Mean MEPP amplitude.

tCalculated using corrected EPP and MEPP amplitudes for a standard RMP of $-80 \mathrm{mV}$ and an ACh reversal potential of $-15 \mathrm{mV}$. 1730 $\ddagger$ Observed $=100 \times$ number of failures of EPP response/number of stimulations. Predicted $=100 \times \mathrm{e}^{-\mathrm{m}} .(21)$

measuring the EPP and MEPP amplitudes at a single endplate with type $C$ responses. Shortly after exposure of the muscle to $0.1 \mathrm{mM} 4-\mathrm{AP}$, EPPs increased in amplitude, approaching the threshold necessary to produce APs (fig 7). Within about five minutes the neuromuscular blockade was reversed and the endplate responded with muscle APs to each nerve stimulation. This reversal of the neuromuscular block was accompained by muscle contractions visibly stronger than those seen prior to application of 4-AP, with eventual displacement of the recording electrode. The mean amplitude of MEPPs measured from the same endplate after exposure to 4-AP was not different from the pre-exposure value. Thus, the increase in EPP amplitude resulted from an increased quantal content, not from increased quantal size or heightened postjunctional membrane sensitivity to ACh. Immediately before the action potentials were elicited, the calculated auantum content of the EPPs was approximately 30, which is three times larger than that calculated without the drug.

The muscle was then exposed to a solution containing $0.4 \mathrm{mM}$ 4-AP. As we have reported in rat skeletal muscle, ${ }^{12} 13$ 4-AP did not affect snontaneous transmitter release (table 1A). MEPP amplitude was slightly increased by this concentration of the drug, this increase being statistically insignificant. No change in MEPP frequency or waveform or RMP was observed. There was, however, a marked modification in the waveform of indirectly elicited muscle APs (fig 6) (table 1B). The repolarising phase of the action potential was prolonged more than three times by the drug with the formation of a pronounced plateau and reduction in the maximum rate of renolarisation. The peak-to-peak amnlitude, rise time, RMP, and the maximum rate of depolarisation of the APs were unchanged.
These results are consistent with the finding that 4-AP inhibits the activation of delayed potassium conductance $\left(\mathrm{G}_{\mathrm{K}}\right)$ in excitable membranes, without interfering with the sodium conductance $\left(G_{x a}\right)$ mechanisms. ${ }^{24}$

\section{Discussion}

The diagnosis of the Eaton-Lambert syndrome is based on weakness that usually predominates distally, and the finding of low amplitude evoked muscle potentials that decrease with repetitive low frequency nerve stimulation but that increase at least $100 \%$ following voluntary or electrical activation of the muscle. Though improvement in strength frequently occurs following muscle activity, such facilitation is not seen in all patients. A poor response or even worsening after graded doses of edrophonium usually distinguishes this defect of neuromuscular transmission from that of myasthenia gravis. Muscle stretch reflexes usually are absent on initial examination, but may be elicited following activation of the appropriate muscle by brief voluntary contraction. Most patients with this condition also have an underlying malignancy, and the prognosis is determined by the neoplasm.

In our patient, multiple factors led to pulmonary insufficiency, but it was felt justified to use 4-AP in an attempt to relieve the component of this insufficiency due to his neuromuscular defect. The clinical and electromyographic examinations demonstrated a beneficial response to the drug, which was somewhat limited by side effects of gastrointestinal hyperactivity.

The electrophysiological data obtained from this patient's muscle biopsy agree with the pathophysiology of the defect of neuromuscular transmission that has been described in the Eaton-Lambert syndrome. MEPPs were of 
normal amplitude and waveform, indicating that the quantal size and postjunctional membrane sensitivity to $\mathrm{ACh}$ were not reduced in this muscle. The indirectly elicited muscle APs were also normal. Despite the large quantal size, neuromuscular transmission frequently failed at many of the junctions examined and this failure, as confirmed by direct quantal analysis, was the result of a reduced number of transmitter quanta released from the motor nerve terminals. The finding of three different types of responses to repetitive stimulation of different fibres demonstrates that there is a variation in the intensity of the neuromuscular blockade at various endplates.

The cause of the deficient release of transmitter quanta in this condition is not known. Neuromuscular blockage qualitatively similar to that present in the Eaton-Lambert syndrome can be found in normal skeletal muscles bathed in high magnesium, low calcium solutions or exposed to botulinum toxin. Since calcium plays a major role in the depolarisation-secretion coupling process at motor nerve terminals, it is possible that the action of calcium ions at the terminal is impaired in the Eaton-Lambert syndrome. Our finding that the frequency of spontaneous transmitter release was only slightly increased by the addition of extracellular calcium in concentrations up to $10 \mathrm{mM}$ suggests that the mechanism for transmitter release in the Eaton-Lambert syndrome has a decreased sensitivity to calcium. Similar findings were demonstrated in a recent electrophysiological study of botulinum toxinpoisoned rats. ${ }^{25}$

Temperature has a marked effect on neuromuscular transmission, which may make it difficult to demonstrate an electromyographic abnormality in myasthenia gravis and in the Eaton-Lambert syndrome in muscles that are not warmed adequately. ${ }^{26}{ }^{27}$ We saw no effect on the evoked muscle potential amplitude response to repetitive stimulation after raising the intramuscular temperature from $32^{\circ} \mathrm{C}$ to $36^{\circ} \mathrm{C}$, a change that usually worsens these measurements in patients with myasthenia gravis. ${ }^{26}$ All in vitro measurements of synaptic events were performed at temperatures of $25^{\circ} \mathrm{C}$ to $27^{\circ} \mathrm{C}$, which could have lessened somewhat the degree of neuromuscular block we saw.

Is a circulating substance responsible for the neuromuscular block in the Eaton-Lambert syndrome? Ishikawa et $a l^{28}$ reported that cancer tissue extract from a patient with this condition produced in vitro a neuromuscular blockade resembling that found in the patient. This finding suggests that the tumour secreted a neuromuscular blocking substance. However, this would not explain the following observations: (1) $30 \%$ of patients with the Eaton-Lambert syndrome have no underlying tumour, (2) clinical improvement or remission of weakness is not related to the size or pathology of the tumour, ${ }^{29}$ and (3) as we and other investigators have demonstrated, no improvement of neuromuscular transmission in vitro occurs after prolonged washing of Eaton-Lambert syndrome muscle. ${ }^{19}$

The beneficial effect of 4-aminopyridine in the Eaton-Lambert syndrome is believed to result from the drug's action in increasing the number of ACh quanta released by nerve impulses. In the present study, we have demonstrated that 4-AP is effective in vivo and in vitro in reversing the neuromuscular transmission blockade of this condition. If this drug proves to be safe for clinical use, it could be useful in the treatment of the Eaton-Lambert syndrome, botulism, myasthenia gravis and other diseases and conditions in which neuromuscular transmission is defective.

This work was supported in part by a centre grant from the Muscular Dystrophy Association, Inc.

\section{References}

1 Eaton G, Lambert EH. Electromyography and electrical stimulation of nerves in diseases of the motor unit: Observations on a myasthenic syndrome associated with malignant tumors. JAMA 1957; 161:1117-24.

2 Elmqvist D, Lambert EH. Detailed analysis of neuromuscular transmission in a patient with the myasthenic syndrome sometimes associated with bronchogenic carcinoma. Mayo Clin Proc 1968; 43:689-713.

3 Brown JC, Johns RJ. Diagnostic difficulties encountered in the myasthenic syndrome sometimes associated with carcinoma. J Neurol Neurosurg Psychiatry 1974; 37:1214-24.

4 Lambert EH. Defects of neuromuscular transmission in syndromes other than myasthenia gravis. Ann N Y Acad Sci 1966; 135:367-84.

5 McQuillen MP, Johns RJ. The nature of the defect in the Eaton-Lambert syndrome. Neurology (Minneap) 1967; 17:527-36.

6 Oh SJ, Kim KW. Guanidine hydrochloride in the Eaton-Lambert syndrome. Electrophysiologic improvement. Neurology (Minneap) 1973; 23: 1084-90.

7 Norris FH, Calanchini PR, Fallat RJ et al. The administration of guanidine in amyotrophic lateral sclerosis. Neurology (Minneap) 1974; 24: 721-8.

8 Norris FH, Eaton JM, Mielke CH. Depression of bone marrow by guanidine. Arch Neurol 1974; 30:184-5. 
9 Cherington M. Guanidine and germine in EatonLambert syndrome. Neurology (Minneap) 1976; 26:944-6.

10 Harvey AL, Marshall IG. The actions of three diaminopyridines on the chick biventer cervicis muscle. Eur J Pharmacol 1977; 44:303-9.

11 Lundh $\mathrm{H}$, Leander S, Thesleff S. Antagonism of the paralysis produced by botulinum toxin in the rat. The effect of tetra-ethylammonium, guanidine and 4-aminopyridine. J Neurol Sci 1977; 32:29-43.

12 Kim YI, Goldner MM, Sanders DB. Facilitatory effects of 4-aminopyridine on normal neuromuscular transmission. Muscle Nerve 1980; 3: 105-111.

13 Kim YI, Goldner MM, Sanders DB. Facilitatory effects of 4-aminopyridine on neuromuscular transmision in disease states. Muscle Nerve 1980; 3:112-9.

14 Lundh $\mathrm{H}$, Nilsson O, Rosén I. 4-aminopyridinea new drug tested in the treatment of EatonLambert syndrome. $J$ Neurol Neurosurg Psychiatry 1977; 40:1109-12.

15 Agoston S, van Weerden T, Westra P, Broekert A. Effects of 4-aminopyridine in Eaton-Lambert syndrome. Brit J Anaesthes 1978; 50:383-5.

16 Elmqvist D, Johns TR, Thesleff S. A study of some electrophysiological properties of human intercostal muscle. J Physiol (Lond) 1960; 154: 602-7.

17 Elmqvist D, Quastel DMJ. A quantitative study of end-plate potentials in isolated human muscle. J Physiol (Lond) 1965; 178:505-29.

18 Albuquerque EX, Rash JE, Mayer RF, Satterfield JR. An electrophysiological and morphological study of the neuromuscular junctions in patients with myasthenia gravis. Exp Neurol 1976; 51: 536-63.

19 Lambert EH, Elmqvist D. Quantal components of end-plate potentials in the myasthenic syndrome. Ann N Y Acad Sci 1971; 183:183-99.
20 Hubbard JI, Llinas R, Quastel DMJ. Electrophysiological Analysis of Synaptic Transmission. Chapter 4: Investigation of Presynaptic Function. Baltimore: Williams and Wilkins, 1969: 112-3.

21 Liley LW. The quantal component of the mammalian end-plate potential. J Physiol (Lond) 1956; 133:571-87.

22 Lambert EH, Lindstrom JM, Lennon VA. Endplate potentials in experimental autoimmune myasthenia gravis in rats. Ann NY Acad Sci 1976; 274:300-18.

23 Lundh $\mathrm{H}$, Nilsson $\mathrm{O}$, Rosén $\mathrm{I}$. Effects of 4-aminopyridine in myasthenia gravis. J Neurol Neurosurg Psychiatry 1979; 42:171-5.

24 Yeh JZ, Oxford GS, Wu CH, Narahasi $\mathrm{T}$. Dynamics of aminopyridine block of potassium channels in squid axon membrane. J Gen Physiol 1976; 68:519-35

25 Cull-Candy SG, Lundh H, Thesleff S. Effects of botulinum toxin on neuromuscular transmission in the rat. J Physiol (Lond) 1976; 260:177-203.

26 Borenstein S, Desmedt J. Local cooling in myasthenia. Arch Neurol 1975; 32:152-7.

27 Ward CD, Murray NMF. Effect of temperature on neuromuscular transmission in the EatonLambert syndrome. $J$ Neurol Neurosurg Psychiatry 1979; 42:247-9.

28 Ishikawa I, Engelhardt JK, Fujisawa T, Okamoto $\mathrm{T}$, Katsuki $\mathrm{H}$. A neuromuscular transmission block produced by a cancer tissue extract derived from a patient with the myasthenic syndrome. Neurology (Minneap) 1977; 27:140-3.

29 Norris FH, Izzo AJ, Garvey PH. Brief report: tumor size and Lambert-Eaton syndrome. In: Brain L, Norris FH, eds. The Remote Effects of Cancer on the Nervous System. New York: Grune and Stratton, 1965: 80-1.

30 Martin AR. A further study of statistical composition of the endplate potential. J Physiol (Lond) 1955; 130:114-22. 